\title{
Effects of synchronous, auditory stimuli on running performance and heart rate
}

\author{
Lisa M. Pfleiderer ${ }^{1, *}$, Lisa Steidl-Müller ${ }^{1}$, Joe Schiltges ${ }^{1} \&$ Christian Raschner $^{1}$ \\ 1 Department of Sport Science, University of Innsbruck, Innsbruck, Austria \\ * Corresponding author: Lisa M. Pfleiderer, Department of Sport Science, University of Innsbruck, \\ Fürstenweg 185, 6020 Innsbruck, Austria \\ Tel: +43 (0) 6765600645 \\ E-Mail: lisa.pfleiderer@student.uibk.ac.at
}

\section{ORIGINAL ARTICLE}

Article History:

Submitted $21^{\text {st }}$ February 2018

Accepted $08^{\text {th }}$ January 2019

Published $12^{\text {th }}$ March 2019

Handling Editor:

Ernst-Joachim Hossner

University of Bern, Switzerland

Editor-in-Chief:

Martin Kopp

University of Innsbruck, Austria

Reviewers:

Reviewer 1: Melvyn Roerdink

Vrije Universiteit Amsterdam, The Netherlands

Reviewer 2: Jasmin Hutchinson Springfield College, Massachusetts, USA

\section{ABSTRACT}

Research has demonstrated that the human being tends to couple body movements and external, acoustic stimuli (metronome or music). This effect is called auditory-motor synchronization. In addition, motivational music possesses characteristics which distract from feelings like fatigue and exertion. Combining these two factors may enhance the sports performance to a greater degree. Therefore, the purpose of this study was to examine 1) the contrast between the influence of no auditory stimulus and accelerated auditory stimuli (by $2 \%$ of the runners' original cadence, as this is the maximum of spontaneous increase) on running performance and 2) the influence of listening to music compared to listening to a metronome on running performance. In this regard, twentyeight sport science students ( 15 females, 13 males) were asked to perform two Cooper tests each. After run 1 (no auditory signal), the sample was divided into two groups. In run 2, which took place on a different day, one group listened to music while running, whereas the other group was stimulated by the sound of a metronome. During the test, distance $(\mathrm{m})$ and average heart rate $(\mathrm{bpm})$ were measured. The results showed that $75 \%$ of all athletes achieved a greater distance under the influence of an acoustic stimulus. Thereby, the running distance changed significantly $(p=0.001)$ by using an acoustic stimulus: $+61 \mathrm{~m}(\mathrm{SD} \pm 100)$ or $2.1 \%$ (SD \pm 3.6$)$. In group 1 (music), the performance improved up to $+3.8 \%$ (SD \pm 3.3 ), a significant difference compared to group 2 (metronome) $(p=$ 0.014), in which no notable change in average heart rate was found. This means that if the tempo of the acoustic stimulus was adapted to the accelerated cadence of an athlete (maximum of spontaneous tempo adaption: $2 \%$ ), improved distances due to the synchronization effect could be achieved. Furthermore, in combination with the motivating qualities of music, improved effects in sport performances could be created.

Keywords:

synchronization - auditory signals - motivational music - running distance

Citation:

Pfleiderer, L. M., Steidl-Müller, L., Schiltges, J. \& Raschner, Ch. (2019): Effects of synchronous, auditory stimuli on running performance and heart rate. Current Issues in Sport Science, 4:005. doi: 10.15203/CISS_2019.005 


\section{Introduction}

In 1998, the Ethiopian distance track and road running athlete Haile Gebrselassie broke several world records, while listening to the rhythmical pop piece "Scatman" by John Scatman and synchronizing his running cadence with the beat of the song (Van Dyck \& Leman, 2016; Karageorghis \& Priest, 2008). Thereby, the effect of coupling physical activity with acoustic, rhythmic signals, "e.g. metronome or music", is called auditory-motor synchronization (Bood et al., 2013; Karageorghis \& Priest, 2008; Large, 2000; Repp, 2005).

Several authors described auditory-motor synchronization as a tool to improve sports performance (Bood et al., 2013; Rendi et al., 2008; Simpson \& Karageorghis, 2006). Also, various studies showed that external, acoustic stimuli can act like a pacemaker, resulting in the regulation of the speed of motion. Acoustic signals are therefore commonly applied in cyclic sports like running, rowing and cycling in order to enhance performance and work rate by stimulating stride frequency and pedalling rate. In this regard, Rendi et al. (2008) compared the impact of fast-and slow-tempo music within a 500-m rowing task. Results thereby showed that the shortest time to completion (TTC) and significantly more rowing strokes per minute (SPM) were achieved in the fast-music condition compared to the slowmusic condition. Furthermore, Simpson \& Karageorghis (2006) found out that synchronizing music and body movement in a 400-m trial led to a significantly faster running time than without music.

Music positively affects physiological parameters in sports (Archana \& Mukilan, 2016; Bacon et al., 2012; Dorris et al., 2016; Savitha et al., 2013; Szmedra \& Bacharach, 1998). For example, Szmedra \& Bacharach (1998) found that listening to classical music during a treadmill running performance significantly decreased the athletes' heart rate, exercise lactate and systolic blood pressure. These positive physiological effects may be partly related to an increased muscular relaxation capability and an elevated blood flow: Music minimized the increase in parameters of the heart rate variability (high frequency, low frequency), resulting in the capability of exercising at a lower heart rate (Archana \& Mukilan, 2016). In addition, Savitha et al. (2013) found that participants who listened to music during sportive activities, showed significantly lower heart rates, oxygen consumption and rates of perceived exertion.

Furthermore, recent studies confirmed that sports performance may be enhanced by making use of the motivational qualities of music (Bood et al., 2013; Chtourou et al., 2017; Dorris et al., 2016; Elliott et al., 2005; Karageorghis \& Priest, 2012; Terry et al., 2012; Yamashita et al., 2006). The results showed that if music contained certain motivational aspects ("e.g. fast, percussive music with accentuated bass frequencies according to Bood et al. (2013)), mood and arousal regulations as well as the distraction from feelings of pain and fatigue were more likely to occur (Bood et al., 2013). Nakamura (2015) investigated accomplished distances in cycling and indicated a significantly positive effect of motivational music $(9.8 \mathrm{~km} \pm 4.6 \mathrm{~km})$ compared to neutral (in terms of motivational qualities) music $(7.1 \mathrm{~km}$ $\pm 3.5 \mathrm{~km}$ ). Furthermore, the participants' perceived exertion was significantly reduced when listening to motivational music compared to non-motivational music (Nakamura, 2015). Marcora et al. (2009) found that uncomfortable acoustic stimuli could also affect the athletes' motivation in a negative way. Thereby, participants listening to non-motivational music reached their individual maximum in perceived exertion faster than those listening to motivational music and abandoned exercising.

In this respect, Karageorghis and Priest (2012) defined four parameters determining the motivational qualities of a musical piece: rhythm (tempo, measured in beats per minute $[\mathrm{bpm}])$, musicality (harmony, melody), cultural relevance and association, whereby music which is particularly linked to personal associations provides significant advantages regarding sports performance, "e.g. maintaining exercise amount or avoiding routine". Further, Bood et al. (2013) examined the relative effects of auditory-motor synchronization and the motivation generated through music on running performance. The participants' performance was thereby compared within three running-to-exhaustion conditions: control condition (no music); metronome condition, matching the athletes' cadence (synchronization) and music condition, again matching the athletes' cadence (synchronization + motivation). In line with the hypothesis, results showed that the factor timeto-exhaustion varied significantly: Time-to-exhaustion was longer in the metronome and motivational music conditions than in the control condition without acoustic stimulus. It was furthermore observed that also the heart rate was affected by acoustic stimuli, more precisely, small to moderate increments in mean heart rate values were studied with acoustic stimuli. In addition, the combination of motivational music with a prominent and consistent beat that matched the athletes' cadence most likely yields optimal effects in terms of running performance (Bood et al., 2013). To the author's knowledge, research on motivational music complementing the possibility of enhancing the individual cadence has not been conducted so far. However, Rendi et al. (2008) for example confirmed that fast music increased the number of strokes per minute and reduced the time to complete a 500-m rowing sprint performance. Studies on running, respectively cycling load were thereby well in line with these results (Van Dyck et al., 2015; Waterhouse et al., 2010). According to Van Dyck \& Leman (2016) as well as Van Dyck et al. (2015), runners weren't able to spontaneously adapt to more than $2 \%$ of their original cadence. Therefore, the aim of this study was to evaluate the contrast between no auditory stimulus and accelerated, auditory stimuli on running performance. The second aim of this study was to examine a possible difference between the influence of listening to music and listening to a metronome on the running performance. It was hypothesized that auditory stimuli, accelerated by $2 \%$ of the original cadence, would have positive effects on running distance and heart rate values. 


\section{Methods}

Participants

Twenty-eight sport science students (15 females, 13 males) aged 23.7 (SD \pm 4.0 ) years participated in the present study. Table 1 shows the students' anthropometric characteristics as well as their average running time per week. These data were collected at the beginning of the test.
Inventory (BMRI), a tool implemented by Karageorghis et al. (1999), known as a valid and objective method to classify the motivational qualities of a song. The musical pieces were then ranked by the categories rhythm, cultural influence, association and musicality. The following four pieces, which achieved the highest "overall motivational quotient", formed the playlist for group 1: 1. Don't Stop Me Now by Queen; 2. Back In Black by ACDC; 3. I'Il Be There For You by The Rembrandts; 4. Gonna Fly Now by Rocky. The tempo of the musical pieces was adapted

Table 1: Anthropometric characteristics among all students comparing group 1 (music) and group 2 (metronome) (means \pm SD)

\begin{tabular}{lccc}
\hline & Group 1 (N=14) & Group 2 (N=14) & Total (N=28) \\
\hline Age [years] & $24.6 \pm 4.0$ & $22.9 \pm 4.0$ & $23.7 \pm 4.0$ \\
Height $[\mathrm{cm}]$ & $174.6 \pm 8.5$ & $174.6 \pm 9.0$ & $174.6 \pm 8.7$ \\
Weight $[\mathrm{kg}]$ & $67.9 \pm 11.9$ & $65.2 \pm 9.9$ & $66.6 \pm 10.8$ \\
BMl $\left[\mathrm{kg} / \mathrm{m}^{2}\right]$ & $22.1 \pm 2.4$ & $21.3 \pm 1.5$ & $21.7 \pm 2.0$ \\
Average running time per week $[\mathrm{h}]$ & $1.8 \pm 1.9$ & $2.0 \pm 3.0$ & $1.9 \pm 2.5$ \\
\hline
\end{tabular}

\section{Procedure}

Each participant completed two Cooper tests on a 400-m athletic track at least seven days apart (the goal of a Cooper test is to complete as much distance as possible within 12 minutes of running; ICC $=0.99$, Alvero-Cruz et al., 2016; $\Phi=0.96$, Penry et al., 2011). On both testing days, the average heart rate was measured by using the M400 Polar watch; the running distance was counted in meters. During the first run, the participants' stride cadence was measured in the sixth and the eighth minute as a mean benchmark, counted together and divided by two, to calculate the runners' individual average stride cadence. For the second run, the group was homogeneously divided into two groups in terms of achieved distance in the first run. Group 1 performed the second run while listening to music, whereas group 2 ran while listening to a metronome. Thereby, the tempo of the acoustic stimulus in group 1 and group 2 matched the participants' individual stride cadence multiplied by 1.02 , according to Van Dyck et al. (2015). The participants in group 2 (metronome), however, could individually choose out of three different rhythms. The musical tracks were selected by the study team and played in a uniform order. The maximum volume for the acoustic stimulus was set to 85 decibels, participants were asked to wear their individual headphones and to avoid maximal exercise 24 hours in advance of the testing. To exclude the possibility of a group facilitation effect, the tests were performed in a staggered manner, with each participant running individually.

The playlist for group 1 (music) was selected from similar previous studies (Dorris et al., 2016; Karageorghis et al., 1999; Karageorghis \& Priest, 2008; Karageorghis \& Priest, 2012). Therefrom, the study team chose ten musical pieces and analysed them by means of the Brunel Music Rating to the participants' individual cadence multiplied by 1.02 using the tool TimeStretch Audio Player.

\section{Statistics}

The data collected were processed by using IBM SPSS Version 24.0 (IBM Corp.) and presented as means and standard deviations as well as absolute and relative frequencies. Verification of normality was thereby analysed with the KolmogorovSmirnov test, so values less than 0.05 were considered statistically significant. The covered running distance respectively mean heart rate measured in run 1 (no stimulus) and run 2 (stimulus) were analyzed with a $2 \times 2$ repeated measures ANOVA to test for main effects of stimulus (run 1 and run 2) and group (music and metronome) as well as interactions stimulus $\times$ group. When a main and/or an interaction effect was found, pairwise comparison with a Bonferroni correction post hoc analysis was applied. Effect size from partial eta ${ }^{2}$ values $\left(\eta^{2} p\right)$ and the observed power were computed. The level of significance was set at $\mathrm{p}<0.05$.

\section{Results}

In $75 \%$ of all participants, a greater distance in run 2 (acoustic stimulus) in comparison to run 1 (no acoustic stimulus) was reported. In total, accomplished running distance significantly increased from run 1 to run 2 (2808 meters vs. 2868 meters) (main stimulus effect: $F(1,26)=12.640, p=0.001, n p^{2}=0.327$, observed power $=0.928$ ). Listening to music in run 2 thereby caused a distance enhancement in $85.7 \%$ of the runners of group 1. In contrast, $64.3 \%$ of the participants performing run 2 in the presence of a metronome increased their running distance. 
Table 2: Average running distances, average heart rates and difference between runs regarding distance and average heart rate among group 1 , group 2 and in total.

\begin{tabular}{|c|c|c|c|c|c|c|}
\hline & & $\begin{array}{c}\text { Run } 1 \\
\text { (no acoustic } \\
\text { stimulus) }\end{array}$ & $\begin{array}{c}\text { Run } 2 \\
\text { (acoustic stimu- } \\
\text { lus) }\end{array}$ & $\begin{array}{c}\text { Difference } \\
\text { between } \\
\text { run } 1 \text { and run } 2\end{array}$ & $\begin{array}{l}\text { Stimulus } \\
\mathrm{x} \text { group }\end{array}$ & group \\
\hline \multirow[t]{3}{*}{ distance $[\mathrm{m}]$} & $\begin{array}{l}\text { group } 1 \\
\text { music }(\mathrm{N}=14)\end{array}$ & $2773 \pm 348$ & $2879 \pm 366$ & $+105 \pm 90$ & $p=0.014$ & $p=0.014$ \\
\hline & $\begin{array}{l}\text { group } 2 \\
\text { metronome } \\
(\mathrm{N}=14)\end{array}$ & $2842 \pm 326$ & $2858 \pm 355$ & $+16 \pm 90$ & & \\
\hline & total $(\mathrm{N}=28)$ & $2808 \pm 332$ & $2868 \pm 354$ & $+61 \pm 100$ & & \\
\hline \multirow[t]{3}{*}{$\begin{array}{l}\varnothing \text { heart rate } \\
{[\text { bpm] }}\end{array}$} & $\begin{array}{l}\text { group } 1 \\
\text { music }(\mathrm{N}=14)\end{array}$ & $182 \pm 10$ & $179 \pm 8$ & $-3 \pm 5$ & $p=0.369$ & $p=0.369$ \\
\hline & $\begin{array}{l}\text { group } 2 \\
\text { metronome } \\
(\mathrm{N}=14)\end{array}$ & $183 \pm 9$ & $182 \pm 12$ & $-0.6 \pm 6$ & & \\
\hline & total $(\mathrm{N}=28)$ & $182 \pm 9$ & $181 \pm 10$ & $-1.5 \pm 5$ & & \\
\hline
\end{tabular}

Significant $p$ values are in italics

The participants' group affected this incline (interaction effect: $F(1,26)=6.929, p=0.014, n p^{2}=0.210$, observed power $\left.=0.717\right)$. Between subject factors revealed no main effects of group $(F(1$, 26) $=0.034, p=0.855, n p^{2}=0.001$, observed power $=0.054$ ). Although the mean heart rate of most of the participants decreased in run 2 (acoustic stimulus) in comparison to run 1 (no acoustic stimulus), no significant reduction of the mean heart rate in the presence of an auditory stimulus compared to no auditory stimulus was found (main stimulus effect: $F(1$, 26) $=2.400, p=0.134, \mathrm{np}^{2}=0.091$, observed power $=0.319$ ) nor any interaction $\left(F(1,26)=0.838, p=0.369, n p^{2}=0.034\right.$, observed power $=0.142)$. Between subject factors revealed no main effects of group $\left(F(1,26)=0.276, p=0.604, \mathrm{np}^{2}=0.011\right.$, observed power $=0.080$ ). Table 2 represents the accomplished running distances, average heart rates and difference between runs regarding distance and average heart rate among group 1, group 2 and in total.

\section{Discussion}

The aim of this study was to evaluate the contrast between no auditory stimulus and accelerated, auditory stimuli on running performance. As a second aim of this study, the contrast between the possible influence of listening to music compared to listening to a metronome on the running performance was examined. Each participant completed two Cooper tests, run 1 without an acoustic stimulus and run 2 while listening to an acoustic stimulus (music or metronome). The results revealed a significant effect of an acoustic stimulus on the accomplished running distance in run 2 in comparison to run 1 (+61 $\mathrm{m} \pm$ 100) $(p=0.001)$. In accordance, studies evaluating the effects of acoustic stimuli on running performance found a significantly longer time-to-exhaustion when listening to music or the beat of a metronome in comparison to no acoustic stimulus (Bood et al., 2013). Furthermore, Bacon et al. (2012) demonstrated that cyclic exercises are performed more efficiently while listening to music, because people synchronise the tempo of their movements with the rhythm of an acoustic stimulus (Karageorghis \& Terry, 1997). Numerous studies discussed the effect of auditory-motor synchronisation on sports performance (Bood et al., 2013; Hohler, 1989; Karageorghis \& Terry, 1997; Rendi et al., 2008; Simpson \& Karageorghis, 2006), finding out that coupling the tempo of the acoustic stimulus and the individual stride cadence results in the optimal effect of auditory-motor synchronisation (Repp, 2005; Roerdink et al., 2011). In the present study, in run 2 the participants were influenced by an acoustic stimulus with the tempo of the runners' individual stride cadence, which had been measured in run 1, accelerated by $2 \%$, as suggested by Van Dyck \& Leman (2016). The aim of this acceleration was to cause the participants to unconsciously synchronise their cadence to the "new" tempo. Consequences of this can be an increased cadence, a higher running tempo and, eventually, a longer accomplished distance. Additionally, listening to music has a distracting effect: Rhythmical stimuli address peoples' attention, resulting in a reduction of the perceived exertion (Karageorghis \& Priest, 2008; Rejeski, 1985).

In the present study, listening to music while running generated a significantly greater accomplished distance than running to the beat of a metronome $(p=0.014)$. However, it must be declared that the initial situation of the groups varied descriptively (group 1, run 1: $2773 \mathrm{~m} \pm 348$; group 2, run 1: $2842 \mathrm{~m} \pm 326)$. One athlete from group 1 had to quit run 2 due to cramps, therefore the initial situation changed retrospectively. A possible effect caused by varying starting situations in groups shall not be precluded, although statistics showed no significant difference between the groups' first 
run ( $p=0.593)$. In contrast to the results of the present study, Bood et al. (2013), who investigated the effects of listening to music compared to listening to the sound of a metronome on the performance during a running task on a treadmill, could not detect a difference between the types of acoustic stimuli. Tenenbaum et al. (2004) described that there are benefits when exercising in the presence of music, which seem to arise due to the motivational qualities of musical pieces. The melody and rhythm of a musical piece was determined to distract the exerciser from feelings like pain, discomfort and fatigue (Tenenbaum et al., 2004). Research links the positive effects of music to its potential ability of controlling arousal, reducing rate of perceived exertion, favouring a positive state of mood as well as a flow state (Karageorghis \& Priest, 2012; Marcora et al., 2009; Nakamura, 2015; Pates et al., 2003). Listening to motivational music while exercising seems to optimize the mind set indirectly, which subsequently increases the athletes' willingness to work harder (Lane et al., 2011; Karageorghis \& Priest, 2008; Waterhouse et al., 2010).

Summing up these results, music seems to enhance performance to a greater degree than the sound of a metronome, which might be due to the more motivational qualities of music. The selection of the playlist in the present study was carefully chosen in terms of motivational characteristics, reflecting and analysing the Brunel Rating Music Inventory as well as existing examples (Dorris et al., 2016; Karageorghis \& Priest, 2012). This could be the reason for a more positive effect in group 1 (music) compared to group 2 (metronome).

In the present study, participants were asked to perform a running task with their individual maximal intensity. The average heart rate decreased by 1.5 beats $(S D \pm 5)$ from run 1 (no acoustic stimulus) to run 2 (acoustic stimulus). Influenced by music, the average heart rate measured 179 beats (SD \pm 8 ) in contrast to 182 beats (SD \pm 10 ) in run 1 (no acoustic stimulus). Nevertheless, no statistically significant reduction $(p=0.134)$ was observed in the average heart rate values when listening to an acoustic stimulus. Studies reported that music stimulates the parasympathetic activity and its heart rate reducing mechanism (Yamashita et al., 2006; Perini et al., 1989). Studies addressing musical therapy even point out the possibility of treating insomnia, anxiety, depression, etc. by using music (Kazemi et al., 2012; Nightingale et al., 2013; Zaza et al., 2005). Bood et al. (2013), examining a high intensity run to exhaustion, accounted increased mean heart rate values when accompanied by acoustic stimuli compared to no acoustic stimulus. According to Bood et al. (2013), participants were able to work at a higher intensity (higher mean heart rate values during high intensity task) for longer.

However, limitations have to be considered. Firstly, a practise effect due to the absence of a control condition cannot be excluded. Secondly, due to the performance level of the sample in the current study, results can only be considered valid for sport science students and young adults who run regularly. Therefore, future expansion should take account of different performance levels, "e.g. top running athletes versus untrained runners". Thirdly, stride rate wasn't measured in run 2; therefore, a synchronization effect cannot be assumed.

In conclusion, by adapting the tempo of an acoustic stimulus to the runners' maximal spontaneous cadence enhancement (original cadence accelerated by $2 \%$ ), the running distances were possibly increased due to auditory-motor synchronisation. Complemented by the motivational qualities of music, a basis for improving running distance of sports students as well as ambitious recreational runners could be generated. Hence, occasionally implementing acoustic stimuli to training sessions could raise motivation as well as running distances.

\section{Funding}

The authors have no funding or support to report.

\section{Competing Interests}

The authors have declared that no competing interests exist.

\section{Data Availability Statement}

All relevant data are within the paper.

\section{References}

Alvero-Cruz, J. R., García, M. G., \& Carnero, E. A. (2017). Reliability and accuracy of Cooper's test in male long distance runners. Revista Andaluza de Medicina del Deporte, 10:61-63. DOI: 10.1016/j.ramd.2016.03.001

Archana, R., \& Mukilan, R. (2016). Beneficial effect of preferential music on exercise induced changes in heart rate variability. Journal of Clinical and Diagnostic Research, 10(5):CC09-CC11. DOI: $10.7860 / J C D R / 2016 / 18320.7740$

Bacon, C. J., Myers, T. R., \& Karageorghis, C. I. (2012). Effect of music-movement synchrony on exercise oxygen consumption. Journal of Sports Medicine and Physical Fitness, 52:359-365

Bood, R. J., Nijssen, M., Van Der Kamp, J., \& Roerdink, M. (2013). The power of auditory-motor synchronization in sports: enhancing running performance by coupling cadence with the right beats. PloS One, 8:e70758. DOI: 10.1371/journal. pone.0070758

Chtourou, H., Hmida, C., \& Souissi, N. (2017). Effect of music on short-term maximal performance: sprinters vs. long distance runners. Sport Sciences for Health, 13:213-216. DOI: 10.1007/s11332-017-0357-6

Dorris, A. E., Quesada, P. M., \& Saleem, J. J. (2016). Effects of Vocal and Instrumental Music on Running. In Proceedings of the Human Factors and Ergonomics Society Annual Meeting, 60:507-511. DOI: 10.1177/1541931213601115 
Van Dyck, E., Moens, B., Buhmann, J., Demey, M., Coorevits, E., Dalla Bella, S., \& Leman, M. (2015). Spontaneous entrainment of running cadence to music tempo. Sports Medicine-Open, 1:15. DOI: 10.1186/s40798-015-0025-9

Van Dyck, E., \& Leman, M. (2016). Ergogenic effect of music during running performance. Annals of Sports Medicine and Research, 3:1082-1085

Elliott, D., Carr, S., \& Orme, D. (2005). The effect of motivational music on sub-maximal exercise. European Journal of Sport Science, 5:97-106. DOI: 10.1080/17461390500171310

Hohler, V. (1989). Sport and music. Sport Science Review, 12:4144

Karageorghis, C. I., \& Terry, P. C. (1997). The psychophysical effects of music in sport and exercise: A review. Journal of Sport Behavior, 20:54-68

Karageorghis, C. I., Terry, P. C., \& Lane, A. M. (1999). Development and initial validation of an instrument to assess the motivational qualities of music in exercise and sport: The Brunel Music Rating Inventory. Journal of Sports Sciences, 17:713-724. DOI: 10.1080/026404199365579

Karageorghis, C., \& Priest, D. L. (2008). Music in Sport and Exercise: An Update on Research and Application. Sport Journal, 11(3).

Karageorghis, C. I., \& Priest, D. L. (2012). Music in the exercise domain: a review and synthesis (Part I). International Review of Sport and Exercise Psychology, 5:44-66. DOI: 10.1080/1750984X.2011.631026

Karageorghis, C. I., \& Priest, D. L. (2012). Music in the exercise domain: a review and synthesis (Part II). International Review of Sport and Exercise Psychology, 5:67-84. DOI: 10.1080/1750984X.2011.631027

Kazemi, S., Ghazimoghaddam, K., Besharat, S., \& Kashani, L. (2012). Music and anxiety in hospitalized children. Journal of Clinical and Diagnostic Research, 6(1):94-96. DOI: JCDR/2012/2641:1831

Lane, A. M., Davis, P. A., \& Devonport, T. J. (2011). Effects of music interventions on emotional states and running performance. Journal of Sports Science \& Medicine, 10:400407.

Large, E. W. (2000). On synchronizing movements to music. Human Movement Science, 19:527-566. DOI: 10.1016/S01679457(00)00026-9

Marcora, S. M., Staiano, W., \& Manning, V. (2009). Mental fatigue impairs physical performance in humans. Journal of Applied Physiology, 106:857-864. DOI: 10.1152/ japplphysiol.91324.2008

Nakamura, P. M. (2015). Music tempo's effect on exercise performance: comment on Dyer and McKune. Perceptual and Motor Skills, 120:860-863. DOI: 10.2466/PMS.110.1

Nightingale, C. L., Rodriguez, C., \& Carnaby, G. (2013). The impact of music interventions on anxiety for adult cancer patients: a meta-analysis and systematic review. Integrative Cancer Therapies, 12:393-403. DOI: 10.1177/1534735413485817

Pates, J., Karageorghis, C. I., Fryer, R., \& Maynard, I. (2003). Effects of asynchronous music on flow states and shooting performance among netball players. Psychology of Sport and Exercise, 4:413-427. DOI: 10.1016/S1469-0292(02)00039-0

Penry, J. T., Wilcox, A. R., \& Yun, J. (2011). Validity and reliability analysis of Cooper's 12-minute run and the multistage shuttle run in healthy adults. The Journal of Strength \& Conditioning Research, 25:597-605. DOI: 10.1519/ JSC.0b013e3181cc2423

Perini, R., Orizio, C., Comandè, A., Castellano, M., Beschi, M., \& Veicsteinas, A. (1989). Plasma norepinephrine and heart rate dynamics during recovery from submaximal exercise in man. European Journal of Applied Physiology and Occupational Physiology, 58:879-883. DOI: 10.1007/BF02332222

Rejeski, W. J. (1985). Perceived exertion: an active or passive process?. Journal of Sport Psychology, 7:371-378. DOI: 10.1123/jsp.7.4.371

Rendi, M., Szabo, A., \& Szabó, T. (2008). Performance enhancement with music in rowing sprint. The Sport Psychologist, 22:175-182. DOI: 10.1123/tsp.22.2.175

Repp, B. H. (2005). Sensorimotor synchronization: a review of the tapping literature. Psychonomic Bulletin \& Review, 12:969-992. DOI: 10.3758/BF03206433

Roerdink, M., Bank, P. J., Peper, C. L. E., \& Beek, P. J. (2011). Walking to the beat of different drums: Practical implications for the use of acoustic rhythms in gait rehabilitation. Gait \& Posture, 33:690-694. DOI: 10.1016/j.gaitpost.2011.03.001

Savitha, D., Sejil, T. V., Rao, S., Roshan, C. J., \& Avadhany, S. T. (2013). The effect of vocal and instrumental music on cardio respiratory variables, energy expenditure and exertion levels during sub maximal treadmill exercise. Indian Journal of Physiology and Pharmacology, 57:159-168

Simpson, S. D., \& Karageorghis, C. I. (2006). The effects of synchronous music on 400-m sprint performance. Journal of Sports Sciences, 24:1095-1102. DOI: 10.1080/02640410500432789

Szmedra, L., \& Bacharach, D. W. (1998). Effect of music on perceived exertion, plasma lactate, norepinephrine and cardiovascular hemodynamics during treadmill running. International Journal of Sports Medicine, 19:32-37. DOI: 10.1055/s-2007-971876

Tenenbaum, G., Lidor, R., Lavyan, N., Morrow, K., Tonnel, S., Gershgoren, A., ... \& Johnson, M. (2004). The effect of music type on running perseverance and coping with effort sensations. Psychology of Sport and Exercise, 5:89-109. DOI: 10.1016/S1469-0292(02)00041-9

Terry, P. C., Karageorghis, C. I., Saha, A. M., \& D'Auria, S. (2012). Effects of synchronous music on treadmill running among elite triathletes. Journal of Science and Medicine in Sport, 15:52-57. DOI: 10.1016/j.jsams.2011.06.003

Waterhouse, J., Hudson, P., \& Edwards, B. (2010). Effects of music tempo upon submaximal cycling performance. Scandinavian Journal of Medicine \& Science in Sports, 20:662669. DOI: 10.1111/j.1600-0838.2009.00948.x

Yamashita, S., Iwai, K., Akimoto, T., Sugawara, J., \& Kono, I. (2006). Effects of music during exercise on RPE, heart rate and the 
autonomic nervous system. Journal of Sports Medicine and Physical Fitness, 46:425-430

Zaza, C., Sellick, S. M., \& Hillier, L. M. (2005). Coping with cancer: what do patients do?. Journal of Psychosocial Oncology, 23:55-73. DOI: 10.1300/J077v23n01_04 
